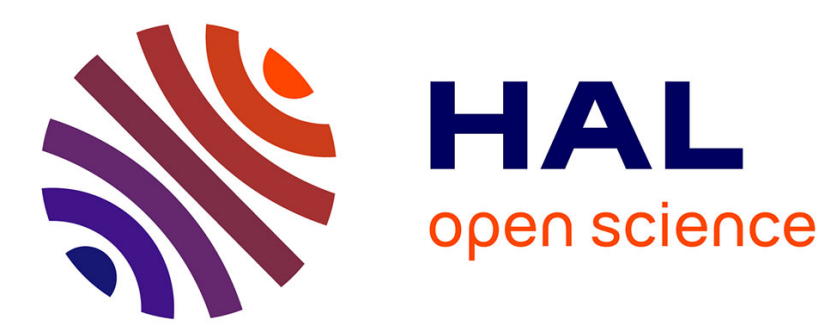

\title{
Implementing Eratosthenes' Discovery in the Classroom: Educational Difficulties Needing Attention
}

\author{
Nicolas Decamp, C. de Hosson
}

\section{To cite this version:}

Nicolas Decamp, C. de Hosson. Implementing Eratosthenes' Discovery in the Classroom: Educational Difficulties Needing Attention. Science and Education, 2012, 21 (6), pp.911-920. 10.1007/s11191010-9286-3 . hal-01663445

\section{HAL Id: hal-01663445 \\ https://hal.science/hal-01663445}

Submitted on 18 Dec 2017

HAL is a multi-disciplinary open access archive for the deposit and dissemination of scientific research documents, whether they are published or not. The documents may come from teaching and research institutions in France or abroad, or from public or private research centers.
L'archive ouverte pluridisciplinaire HAL, est destinée au dépôt et à la diffusion de documents scientifiques de niveau recherche, publiés ou non, émanant des établissements d'enseignement et de recherche français ou étrangers, des laboratoires publics ou privés. 


\title{
Implementing Eratosthenes' Discovery in the Classroom: Educational Difficulties Needing Attention
}

\author{
Nicolas Décamp • Cécile de Hosson
}

(C) Springer Science+Business Media B.V. 2010

\begin{abstract}
This paper presents a critical analysis of the accepted educational use of the method performed by Eratosthenes to measure the circumference of Earth which is often considered as a relevant means of dealing with issues related to the nature of science and its history. This method relies on a number of assumptions among which the parallelism of sun rays. The assumption of sun rays parallelism (if it is accurate) does not appear spontaneous for students who consider sun rays to be divergent. Here, we propose an educational reconstruction of Eratosthenes' discovery based on the exploitation of a narrative written by Cleomedes during the first century AD. This implies that the students are involved in an elaboration of parallelism by an approach where the notion of "approximation" remains central.
\end{abstract}

\section{Introduction}

Many researches in science education show that incorporating aspects of science history helps students learn both science content and the nature of science (NOS). The use of science history can potentially provide a more consistent view of science, promote a deeper understanding of scientific concepts and address common student misconceptions that often resemble those of scientists of the past (Matthews 1994). In that perspective, the use of Eratosthenes' measurement of Earth's circumference has become one of the

N. Décamp $(\bowtie)$

Lycée Condorcet, Montreuil, France

e-mail: decamp@laposte.net

C. de Hosson

Laboratoire de didactique André Revuz, Physics Department, Université Paris Diderot, Paris, France e-mail: cecile.dehosson@univ-paris-diderot.fr 


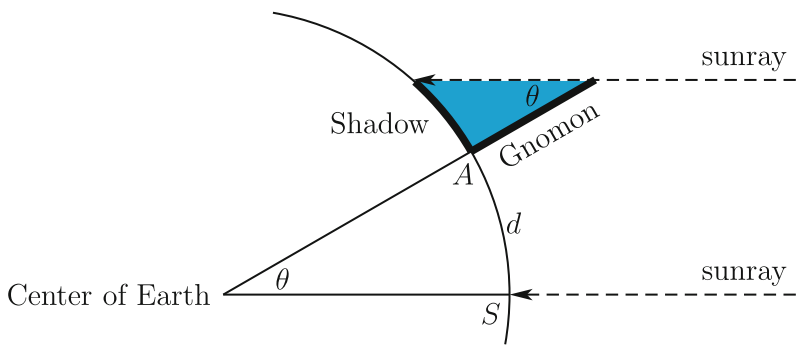

Fig. 1 Usual illustration of Eratosthenes' measurement. He measured the length of the gnomon and its shadow at noon at Alexandria. Then he determined the angle of sunlight with the vertical, which is the same as the angle subtended by Syene $(S)$ and Alexandria $(A)$ at the center of Earth

paradigmatic science teaching activities in many countries (Bozic and Ducloy 2008). This historical method of measurement is ritually used as follows. ${ }^{1}$

The first step usually provides students with some information about Eratosthenes' observations and procedure such as: Eratosthenes was a Greek living in Alexandria (northern Egypt), in the third century, BC. He knew that on a certain day at noon in Syene (south of Alexandria and on the same meridian), the sun shone straight down a deep well. Eratosthenes also knew that when the sun was directly overhead in Syene, it was not directly overhead in Alexandria because obelisks and gnomons cast a shadow. From the length of the shadow, the height of the object, and the distance between Syene and Alexandria, he calculated the circumference of Earth.

The second step consists in using a diagram to geometrically interpret Eratosthenes observations using the assumptions that the Earth is round and the Sun's rays are parallel (Fig. 1). Students may probably find that the angle formed by a gnomon and an imaginary line from the end of the shadow to the top of the gnomon equals the angle at the Earth's center formed by imaginary lines coming from the two towns. The Earth's circumference can be obtained by measuring the distance between Alexandria and Syene, and multiplying it by the number of times the angle at Earth's center can be found in 360 degrees.

Thirdly the students must determine the angle at the top of the gnomon. In some teaching sequences, the value of this angle is given to the students $\left(\theta=7.2^{\circ}\right)$. Sometimes, they must calculate the angle by using information given on the length of the shadow cast by the gnomon and the gnomon's length itself. Considering that the gnomon and its shadow form two sides of a right-angled triangle, the shadow's length, the gnomon's height and the angle are related by:

$$
\tan \theta=\frac{\text { length of shadow }}{\text { height of gnomon }}
$$

The Earth's circumference $C_{E}$ is given by the following formula in which the distance between Alexandria and Syene is $d$ (the procedure used by Eratosthenes to measure $d$ varies from one teaching sequence to another):

$$
C_{E}=\frac{360}{\theta} d
$$

\footnotetext{
1 see for example http://www.physics2005.org/projects/eratosthenes/ or http://www.ciese.org/curriculum/ noonday/.
} 
The following sections discuss the relevance of this activity both from an historical and educational perspective.

\section{Historical Elements}

Unfortunately, Eratosthenes' original writings on the measurement of the Earth (2 books) were lost. We have access to his work only through writers of antiquity such as Cleomedes, Pliny, Strabo. The most detailed among these writings is a short review by Cleomedes. Although this review is very short (less than one page), we will focus on this testimony for two reasons:

- it is the only one which gives us some details on the method used by Eratosthenes.

- it is the original base for almost any didactical transpositions even when the text is not quoted as such.

The transposition in the classroom of Eratosthenes' method relies on the evaluation of the angle $\theta$ and usually involves trig calculations. Such transposition appears totally anachronic as the tangent had not yet been invented.

We are told by Cleomedes (see the translation of On the circular motion of the celestial bodies, book 1, Chap. 7, in "Appendix") that Eratosthenes made measurements with a gnomon that cast a shadow onto the graduated inner surface of a hemispherical sundial named scaphe (Fig. 2). The shadow cast by the gnomon on the sundial reaches an arc equal to $1 / 50$ th of a circle from the base of the gnomon (Fig. 3). This very simple process is challenged by some historians and philosophers (Goldstein 1984; Bowen 2008). However, if the scaphe has been used, it seems very unlikely that the surface of a scaphe would have been devided in fiftieths. A more reasonable assumption would be to divide the surface by twelve and then by four, to reach 1/48th, which was a common assumption of the angle between Syene and Alexandria (Rawlins 1982).

The method Eratosthenes used to compute the distance between Syene and Alexandria has also been subject to debate. Some historians even claimed he used the daily distance travelled by camel caravans. This seems very unlikely, as Camels were imported under Alexander but did not become common until the Christian's era. The method used was most likely based on maps of Egypt or accurate distance estimations made by bematists.

Fig. 2 Diagram of a scaphe

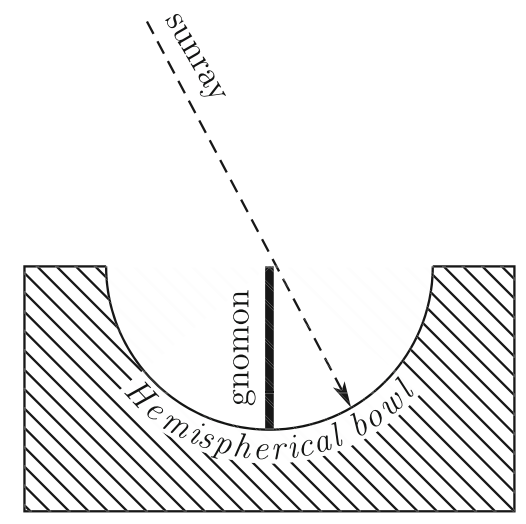




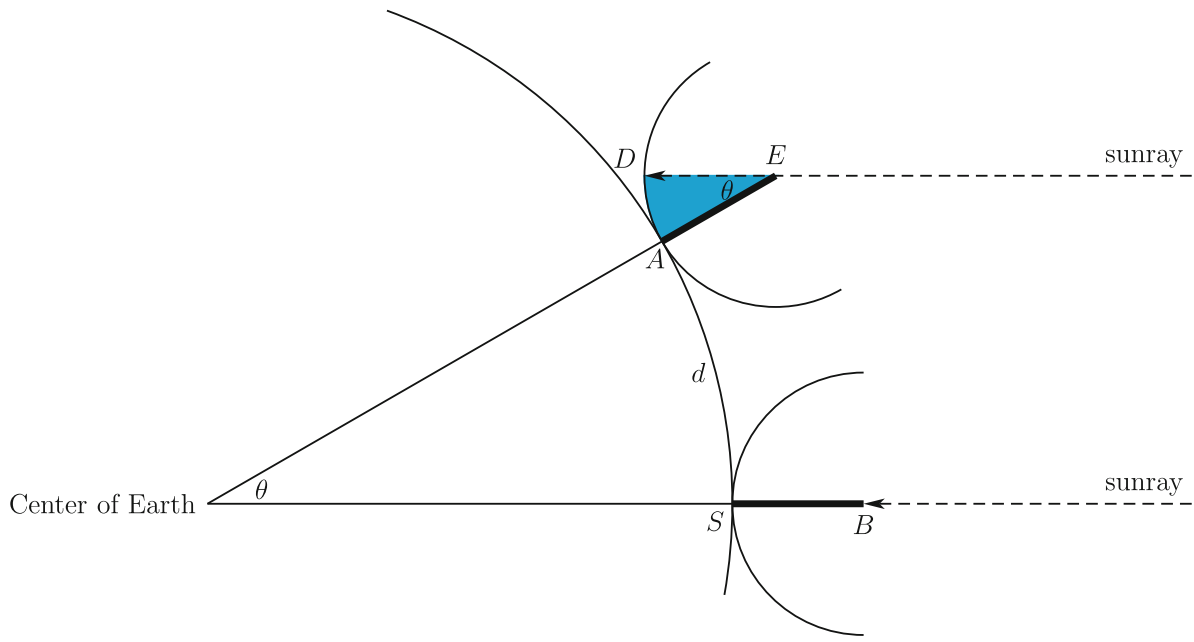

Fig. 3 Illustration of Eratosthenes' procedure as described by Cleomedes in On the circular motion of the celestial bodies (book 1, Chap. 7). The shadow $A D$ cast by the gnomon in the hemispherical sundial reaches an arc equal to 1/50th of a circle of radius $A C$. The ratio of 1/50th of the circumference of the Earth corresponds to the distance $A E$ between Alexandria and Syene (Weir 1931)

These men were trained to make regular paces when marching from one place to another and to record their numbers (Dutka 1993).

\section{Focusing on the Parallelism of Sunrays}

\subsection{Why can We Consider Sunrays as Parallel Lines?}

The Sun is not a point source of light but an extended one and its angular diameter is about $0.52^{\circ 2}$. Half of the Earth's surface is struck by an infinite number of cones, each containing an infinite number of rays sent out by each point of the Sun.

In Fig. 4 we have illustrated two of those cones reaching the towns of Alexandria and Syene. One must consider that the angle $C_{t} \widehat{A C}_{b} \simeq \widehat{C}_{t} \widehat{S C}_{b} \simeq 0.52^{\circ}$. This angle is small because the diameter of the Sun $\left(C_{t} C_{b}\right)$ is small with respect to the distance between Sun and Earth. This is the reason why the Sun can roughly be considered as a point source. In the same picture we see that the angle $\widehat{A C S}$ is even smaller. Therefore the sun's rays can be considered parallel. This clarification illustrates the complexity of the process underlying the hypothesis of parallelism of sunrays, which at the scale of a portion of 1/50th (or $1 /$ 48th) of the Earth's circumference remains an approximation. Similarly the assimilation of the Sun to a single point stems from an identical complexity. Yet, the fact that the Sun is an

\footnotetext{
${ }^{2}$ Which means that there is actually a range of locations for which the Sun is "directly overhead" at a given time. In Cleomedes' essay one of the values given for the angular diameter of the Sun was estimated to be 1/ 750 th of a complete circle, or in more modern units $0.48^{\circ}$. The method he mentions consists in mesuring the time $t_{1}$ between the instant when the Sun reaches the horizon at sunset and its definite disappearance. Then he found that the duration of one day equals $750 \times t_{1}$ and concluded that the angular diameter of the Sun equals $1 / 750$ th of a complete circle
} 


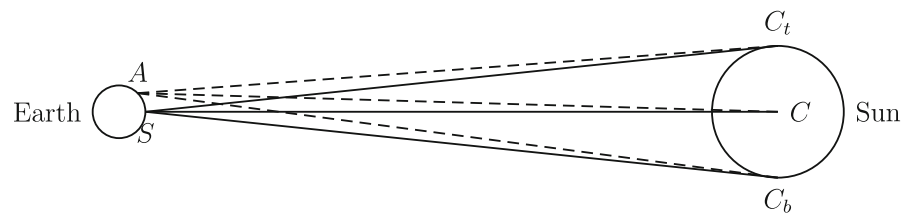

Fig. 4 Illustration of two cones of light coming from the Sun and reaching Syene $(S)$ and Alexandria $(A)$. Figure not drawn to scale: $\widehat{C}_{t} \widehat{A C}_{b} \simeq \widehat{C}_{t} \widehat{S C}_{b} \simeq 0.52^{\circ}$ whereas $\widehat{A C S} \simeq 1.1^{\prime \prime}$

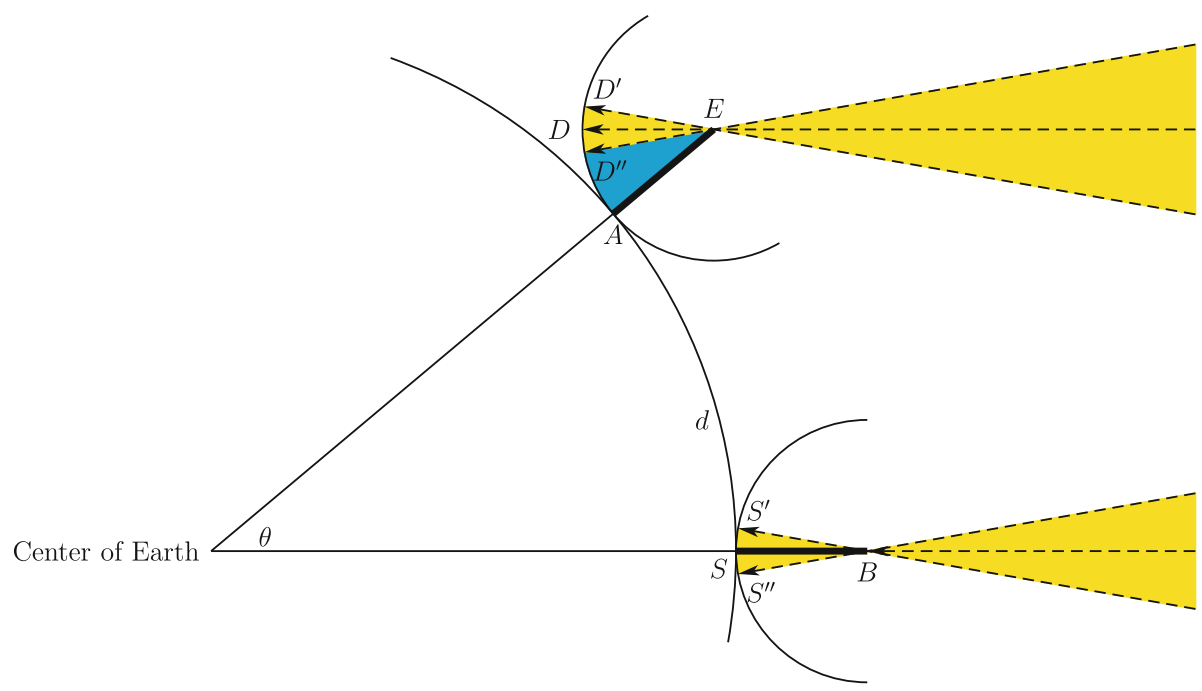

Fig. 5 The dashed lines model the propagation of the light responsible for the shadows and partial shadows cast by $A E$ and $S B$ gnomons respectively located in Alexandria and Syene. For the sake of clarity the size of the Sun's apparent angular diameter is greatly exaggerated

extended source explains that the shadows cast by gnomons are surrounded with a partial shadow area.

Figure 5 is an extract of the preceding figure: the dashed lines model the propagation of a part of the light emitted by the uppermost, lowermost and center points of the Sun on two different parts of the Earth (Alexandria and Syene). The upper lines delimit the shadows $A D^{\prime \prime}$ and the partial shadows $D^{\prime \prime} D^{\prime}$ cast by a gnomon located in Alexandria. The lower lines delimit two partial shadows $S S^{\prime}$ and $S^{\prime} S^{\prime \prime}$ cast by a gnomon in Syene. The middle dashed line shows a sunray coming from the center of the Sun. Because of the Sun's angular diameter of $0.5^{\circ}$, the partial shadow $D^{\prime \prime} D^{\prime}$ is 14 times smaller than the shadow $A D^{\prime \prime}$ and can therefore be neglected. We also find that the partial shadows $S S^{\prime}$ and $S S^{\prime \prime}$ are defined by angles of $0.25^{\circ}$. For a $1 \mathrm{~m}$ height gnomon, these areas do not exceed $4 \mathrm{~mm}$ in length and are barely perceivable.

Since the Sun is a very distant source, the rays emitted by one point of the Sun connecting two different points on Earth (e.g., the rays connecting a point in the center of the Sun and the points $D$ and $S$ ) can be considered as parallel. The Fig. 6 shows a point $C$ at the center of the Sun. If the Sun is close to the Earth, two rays from point $C$ define a cone that is a right-angled triangle $E C B$. Further the Sun is away, smaller is the angle $\hat{C}$, and more parallel are the sunrays. Therefore, in the right-angled triangle $E B C$ we have: 


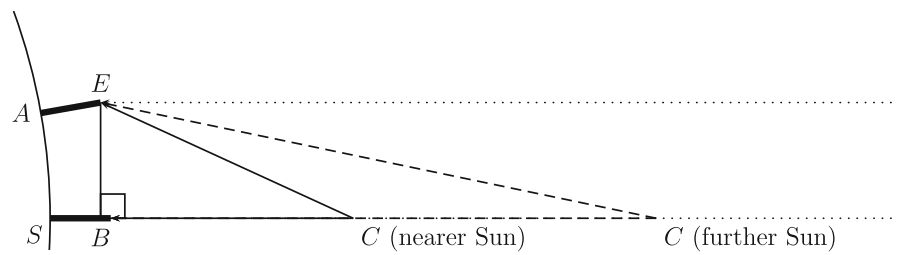

Fig. 6 Further the Sun is away, smaller is the angle $\hat{C}$, and more parallel are the lines

$$
\begin{gathered}
\hat{E}+\hat{B}+\hat{C}=180^{\circ} \\
\hat{E}=180^{\circ}-\hat{B}-\hat{C} \\
\hat{E}=90^{\circ}-\hat{C} \\
\hat{E} \simeq 90^{\circ} \text { since } \hat{C} \text { is small }
\end{gathered}
$$

\subsection{Cleomedes and the Assumption of the Parallelism of the Sun Rays}

According to Cleomedes, the measure of the circumference of the Earth is based on several assumptions. The parallelism of the solar rays is the third assumption. If we pay attention to the way this parallelism is justified, we find that the Sun is considered as sending parallel rays from each part:

Since the horologe in Syene lies perpendicularly under the sun, we may perceive that the straight line coming from the sun to the summit of the gnomon becomes one straight line with that from the sun to the centre of the earth. And if we imagine another straight line drawn from the end of the shadow of the gnomon in Alexandria to the sun, this and the aforesaid straight line will be parallels, extending from different parts of the sun into different parts of the earth (Weir 1931).

It seems that in Cleomedes' view the correspondence between a single point from the Sun and a single point on the Earth is done by a single ray and not by a cone containing a set of rays emanating from a single point. This is surprising because it was known since Aristotle that a cone making the convergence of the sunrays emanates from the Sun and embraces the Earth (Aristotle, Meteorologica, i,8, 345, 1-9). Furthermore this theory can be found in another section of Cleomede's essay, when he refers to the eclips.

\subsection{Children's Spontaneous Assumption of the Divergent Rays}

When students are asked to explain why on the same day (summer solstice), at noon, the obelisk casts a shadow in Alexandria and not in Syene, two cities along the same meridian, they generally offer the type of diagram suggested in Fig. 7 (Merle 1994). In most cases, the propagation of light coming from the Sun is shown with divergent rays. The prototypical diagram as presented in Fig. 7 suggests that the Sun is considered as a close source whereas students probably know that the distance between the Sun and the Earth is considerable. Yet, they do not apply this knowledge practically. In other words, students fail to translate the geometrical consequences of Earth-Sun distance; especially since the divergent rays reasoning appears fully operational. This difficulty is echoed in the "naive" model spontaneously used by students when explaining shadow formation at a single 


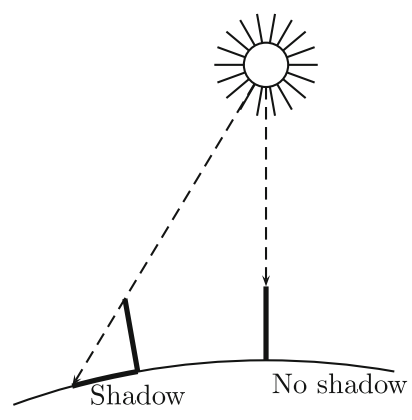

Fig. 7 Prototypical drawing proposed by students who are asked to explain why during summer solstice at noon, the obelisk casts a shadow in Alexandria and not in Syene. Students usually draw non-parallel rays coming from a near Sun down onto a spherical (or a plane) surface of the Earth. According to Feigenberg et al. (2002), ignoring the distance of the Sun (or the curvature of the Earth) is not connected with the lack of scientific knowledge but with difficulties in understanding large dimensions and in the relationship between various parameters: the distance to the Sun, the dimensions of the Earth, their impact on observed phenomena

location (Douek 1999). Thus, using the historical assumption of parallel rays requires students to change their way of representing light propagation coming from the Sun. That is, moving from the spontaneous model of divergent rays to a model involving parallel rays

\subsection{Considering the Assumption of the Parallelism of Sun Rays as a Conceptual Change: Educational Perspective}

In the paradigmatic view of Eratosthenes' teaching sequence, the assumption of the parallelism of the sun rays is usually given as such to the students, and the fact that the Sun is an extended source of light is rarely discussed. In some cases, the assumption of parallel rays is constructed on the basis of local observations (e.g., across a sheet of paper) considering parallel shadows cast by vertical sticks placed next to each other. ${ }^{3}$ This activity implies that the assumption of the parallel rays elaborated by students from experiments locally performed still remains relevant for the observations they are given at a different scale (e.g., the distance between Alexandria and Syene). Moreover, following Galili's research on the "hybrid post-instructional knowledge" concept in geometrical optics (Galili 1996), we assume that this process may lead students to develop an intermediate model where the Sun would be considered as sending horizontal parallel rays from each point (a point-to-point horizontal line correspondence model). This hybrid view is close to Cleomedes' one but contrasts with the scientific view elaborated in "point-to-point flux mapping" conceptualization.

As noted by Feigenberg et al. (2002) it is impossible to show on the same picture the curvature of the Earth and the distance between Earth and Sun preserving correct ratios. They suggest to remove part of the picture and present this part in an other scale, the socalled "Zoom Method". Our suggestion is to make use of Cleomedes' narrative (see "Appendix") in the Monk and Osborne's (Monk and Osborne 1997) pedagogical model perspective (Table 1). The idea is to involve the students in an activity where they may discover the reason why the light emitted by a very distant point source can be modeled with parallel lines starting from their spontaneous cone representation as shown in Fig. 7.

\footnotetext{
3 see for example http://www.lamap.fr/eratos
} 
Table 1 Model of the Monk and Osborne's teaching process (Monk and Osborne 1997) adapted to a teaching-learning scenario build upon Cleomedes' narrative

\begin{tabular}{|c|c|c|}
\hline Phase & Students & Product \\
\hline $\begin{array}{l}\text { 1. Presentation of } \\
\text { phenomenon }\end{array}$ & $\begin{array}{l}\text { Can you explain why during summer } \\
\text { solstice at noon, the obelisk casts a shadow } \\
\text { in Alexandria and not in Syene? }\end{array}$ & \\
\hline $\begin{array}{l}\text { 2. Elicitation of } \\
\text { students' ideas }\end{array}$ & $\begin{array}{l}\text { - Students provide explanations involving: } \\
\text { - Prototypical cone reasoning } \\
\text { - Parallel rays reasoning } \\
\text { - etc. }\end{array}$ & $\begin{array}{l}\text { A range of ideas about the reasons why } \\
\text { two differently located gnomons cast } \\
\text { different shadows }\end{array}$ \\
\hline 3. Historical study & $\begin{array}{l}\text { Study of Cleomedes' narrative (Sudents are } \\
\text { given information about horologes) using } \\
\text { the following questions: } \\
\text { - Make a drawing to sum up Eratosthenes' } \\
\text { measurements as reported by Cleomedes. } \\
\text { - Compare your former drawing with the } \\
\text { one you obtained following Cleomedes' } \\
\text { narrative. } \\
\text { - Discuss the sentence: "if we imagine } \\
\text { another straight line drawn from the end of } \\
\text { the shadow of the gnomon in Alexandria to } \\
\text { the sun, this and the aforesaid straight line } \\
\text { will be parallels, extending from different } \\
\text { parts of the sun into different parts of the } \\
\text { earth". }\end{array}$ & $\begin{array}{l}\text { Emergence of a conflict between the } \\
\text { spontaneous way of drawing the } \\
\text { propagation of sun rays and the } \\
\text { drawing performed following } \\
\text { Cleomedes' narrative. }\end{array}$ \\
\hline 4. Devising test & $\begin{array}{l}\text { Students can model the propagation of light } \\
\text { emitted by one point source using two two- } \\
\text { meters long strings attached to the same } \\
\text { nail. They observe that the extremities of } \\
\text { the strings are nearly parallel. }\end{array}$ & \\
\hline $\begin{array}{l}\text { 5. The scientific } \\
\text { idea }\end{array}$ & $\begin{array}{l}\text { Students are asked to discuss the value of the } \\
\text { angle } \hat{C} \text { of the cone formed by the Sun and } \\
\text { the two extremities of the shadows when } \\
C \text { moves away from the Earth (see Fig. } 6 \text { ). }\end{array}$ & $\begin{array}{l}\text { An understanding of the parallelism } \\
\text { of sun rays }\end{array}$ \\
\hline $\begin{array}{l}\text { 6. Review and } \\
\text { evaluation }\end{array}$ & Evaluation and discussion of the evidence & $\begin{array}{l}\text { An understanding of Eratosthenes' } \\
\text { method as reported by Cleomede }\end{array}$ \\
\hline
\end{tabular}

The teaching sequence could end on a critical discussion concerning the different ways of representing the propagation of light coming from the Sun according to the involved celestial phenomena. Indeed, as we detailed previously, the parallelism of the sunrays is an approximation quite relevant to reproduce the measure of the Earth's circumference as reported by Cleomedes. The same approximation is traditionally used to explain the alternation of day and night and the temperature changes according to the seasons, but this approximation does wrongly explains the eclipses. Indeed, the representation of the propagation of the light coming from the Sun with cones emitted by several points on the surface of the Sun becomes necessary to understand the partial eclipse of the Sun for example. This current change in the representation of the propagation of the light emitted by the Sun is rarely discussed in the classroom, and both representations (parallel sunrays and cones) often coexist in the same textbooks or websites. An activity based on Cleomedes' narrative could be an opportunity to approach certain aspects of the nature of 
science, including the notions of model and approximation, their relevance and consistency.

\section{Conclusion}

A great number of teaching materials have been elaborated in order to make students "follow the footsteps of Eratosthenes". These sequences usually aim to involve students in a rediscovery process in order to promote a more appropriate image of science. In that perspective, the individual learning pathway is implicitly considered to be potentially identical to the pretended historical one. In fact, Eratosthenes' measurement as reported in Cleomedes' narrative leans on several assumptions including the sun rays parallelism which is far from being intuitive. The spontaneous model of the divergent rays performed by students to show the sun light propagation is perfectly available: from one point source are emitted an infinite number of rays and the Earth is embraced by an infinite number of cones emitted by each point of the Sun. The major difficulty is to make students admit that since the Sun is a very distant source and that the open angle of each cone can be considered as equal to zero while avoiding the appearance of the "point-to-point horizontal line correspondence" hybrid idea staged in Cleomedes' narrative.

Anyway, the historical assumption of the sun rays parallelism is far from being a spontaneous assumption for the students and thus, should be considered as a specific learning target. This could not be disconnected from a specific work including a reflection on the concept of model and the notion of approximation.

Finally, placing students in a strict rediscovery process may lead to miss a deep cognitive obstacle related to light propagation. Consequently, Eratosthenes' measurement cannot be effectively integrated into science content instruction without being adapted to the cognitive constraints that govern the individual learning process. This implies a particuliar care on what science is and a specific reconstruction where the use of a historical source (Cleomedes' narrative) plays a crucial part.

\section{Appendix}

Weir J. (1931). The method of Eratosthenes, Journal of the Royal Astronomical Society of Canada, 25, 294-297:

Syene and Alexandria, says Eratosthenes, lie under the same meridian (Weir 1931). And since the meridians are the greatest circles in the universe, necessarily those that underlie them are the greatest circles of the erath. Accordingly, whatever size the method may prove for the circle of the earth trough Syene and Alexandria, the same will be the size of the great circle of the earth. Also, he maintains, Syene lies under the circle of the summer solstice. Whenever then the sun, being in Cancer and making the summer tropics, comes exactly to mid-heaven, the gnomons of the horologes must become shadowless, the sun being perpendicularly above, precisely, and this becomes the rule over a diameter of three hundred stadia.

In Alexandria, at the same hour, the gnomons of the horologes throw a shadow, in as much as this city lies more to the north than Syene. If now, in the meridian and the great circle of the cities, we draw a periphery from the end of the shadow of the gnomon in Alexandria upon the basin of the horologe itself, the periphery will become the graduation mark of the great circle among those in the bowl, since the shadow underlies a great circle. 
If, thereafter, we imagine straight lines extended through the earth from each of the gnomons, these lines will meet at the centre of the earth. Since the horologe in Syene lies perpendicularly under the sun, we may perceive that the straight line coming from the sun to the summit of the gnomon becomes one straight line with that from the sun to the centre of the earth. And if we imagine another straight line drawn from the end of the shadow of the gnomon in Alexandria to the sun, this and the aforesaid straight line will be parallels, extending from different parts of the sun into different parts of the earth. Upon these lines, which are parallel, falls the straight line coming from the centre of the earth to the gnomon in Alexandria so as to make the alternate angles equal. Of these angles, one is at the centre of the earth at the junction of the straight lines produced from the horologes to the centre, and one at the junction of the summit of the gnomon in Alexandria with the line from the end of its shadow produced toward the sun through the tangency.

Now upon this latter angle was placed the periphery drawn from the end of the shadow and around the basin. Upon that at the centre of the earth lies the periphery from Syene to Alexandria. Now those peripheries are like which lie upon equal angles.

Whatever proportion then the arc in the scaphe holds to its complete circle, the arc from Syene to Alexandria holds the same. But the arc in the scaphe is found to be the one-fiftieth part of the whole circle. Necessarily, therefore, the interval from Syene to Alexandria is the fiftieth part of the great circle of the earth. And this is five thousand stadia. Hence, the whole circle becomes 25 myriad $(250,000)$ stadia.

And such is the method of Eratosthenes.

\section{References}

Bowen, A. (2008). Cleomedes and the measurement of the Earth: A question of procedures. Centaurus, 50, 195-204.

Bozic, M., \& Ducloy, M. (2008). Eratosthenes' teachings with a globe in a school yard. Physics Education, 43(2), 165-172.

Douek, N. (1999). Argumentation and conceptualization in context: A case study on sun shadows in primary school. Educational Studies in Mathematics, 39, 89-110.

Dutka, J. (1993). Erathostenes' measurement of the earth reconsidered. Educational Studies in Mathematics, 46(1), 55-66.

Feigenberg, J., Lavrik, L. V., \& Shunyakov, V. (2002). Space scale: Models in the history of science and students' mental models. Science \& Education, 11, 377-392.

Galili, I. (1996). Students' conceptual change in geometrical optics. International Journal of Science Education, 18(7), 847-868.

Goldstein, B. (1984). Eratosthenes on the "measurement" of the Earth. Historia Mathematica, 11, 411-416.

Matthews, M. (1994). Science teaching: The role of history and philosophy of science. New York: Routledge.

Merle, H. (1994). Sensibilisation à l'histoire des sciences d'enfants de 9 à 11 ans : l'expérience d'Eratosthène. In: A. Giordan, J.-L. Martinand, \& D. Raichvarg (Eds.), Actes des XVIIe Journées Internationales sur l'Enseignement des Sciences (Paris) (pp. 475-480). Paris: Université Paris 7.

Monk, M., \& Osborne, J. (1997). Placing the history and philosophy of science on the curriculum: A model for the development of pedagogy. Science Education, 81(4), 405-424.

Rawlins, D. (1982). Eratosthenes' geodesy unraveled: Was there a high-accuracy hellenistic astronomy? Isis, 73(2), 259-265.

Weir, J. (1931). The method of Eratosthenes. The Journal of the Royal Astronomical Society of Canada, 25, 294-297. 